\title{
Commentary: Size matters, but not as much as surgeon preference
}

\author{
Brandon M. Wojcik, MD, and \\ T. Brett Reece, MD, MBA
}

Determining the ideal time to intervene for an ascending aortic aneurysm is, to say the least, complicated. The goal remains finding the optimal timeframe during which the risk of an acute aortic event outweighs the risk of surgery. In this issue of the Journal, the Canadian Thoracic Aortic Collaborative demonstrates that given differences in society guidelines, there exists practice variation among surgeons. ${ }^{1}$ Their group should be commended for ascertaining the size threshold for a variety of patient presentations among both high-volume and low-volume surgeons at 25 centers across Canada. Although current Canadian, American, and European guidelines agree on $5.5 \mathrm{~cm}$ as an absolute size threshold for a healthy, asymptomatic patient with a tricuspid aortic valve, they differ in recommendations for risk factors and an annual growth rate that should prompt earlier intervention. ${ }^{2-4}$ Without the aid of a crystal ball, cardiac surgeons must consider and balance a variety of patient and physician factors in making this decision.

A thorough history, physical examination, and review of the medical record are critical in identifying pertinent risk factors. Prophylactic repairs at lower size thresholds are advised for patients undergoing a concomitant cardiac surgery $(4.5 \mathrm{~cm})$ or diagnosed with a connective tissue disorder $(4.5-5.0 \mathrm{~cm}){ }^{4}$ In healthy asymptomatic patients who do not meet one of the aforementioned criteria, we consider earlier surgery if they have a family history of dissection, rapid growth, occupational risk factors, or meet the criteria of the Aortic Size Index. A family history of dissection is the only agreed-upon risk factor among all the guidelines,

\footnotetext{
From the Division of Cardiothoracic Surgery, Department of Surgery, University of Colorado, Aurora, Colo.

Disclosures: The authors reported no conflicts of interest.

The Journal policy requires editors and reviewers to disclose conflicts of interest and to decline handling or reviewing manuscripts for which they may have a conflict of interest. The editors and reviewers of this article have no conflicts of interest.

Received for publication Feb 4, 2021; revisions received Feb 4, 2021; accepted for publication Feb 5, 2021; available ahead of print Feb 16, 2021.

Address for reprints: T. Brett Reece, MD, MBA, University of Colorado Hospital, 12631 E 17th Ave, Mail Stop C3110, Aurora, CO 80045 (E-mail: brett.reece@ cuanschutz.edu).

J Thorac Cardiovasc Surg 2023;165:28-9

0022-5223/\$36.00

Copyright (c) 2021 Published by Elsevier Inc. on behalf of The American Association for Thoracic Surgery

https://doi.org/10.1016/j.jtcvs.2021.02.022
}

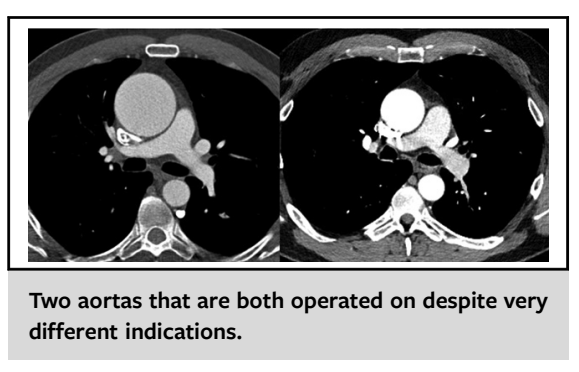

CENTRAL MESSAGE

Although guidelines suggest cutoffs for intervention, not all surgeons see these guidelines the same way.

and it is not surprising that $92.8 \%$ of respondents lowered their threshold for surgery when this history was present. ${ }^{1}$ Time must be taken to truly delve into the family history, as aortic dissection is present more often than one may think. Finally, patients with severe anxiety over knowledge of their aortic aneurysm that limits their quality of life or prompts frequent cross-sectional imaging may benefit from early repair.

The cardiac surgeon's experience with performing aortic surgery and knowledge of their individual complication rates should also factor into the equation. There has been a trend in the field of aortic surgery to intervene at a lower diameter to prevent dissection or rupture as studies show that modern day elective aortic surgery is safer. ${ }^{5}$ While it is not a recommendation in current guidelines, we agree with $20 \%$ of survey respondents who advocate offering surgery at $5.0 \mathrm{~cm}$ to the average patient. ${ }^{1}$ This lower size threshold is one reason why the presence of a bicuspid aortic valve rarely factors into our decision making process.

At the end of the day, the patient and surgeon must form a plan that both are comfortable with. The vast majority of patients do not require referral to an aortic center of excellence; however, for cardiac surgeons who do not want to practice outside of guideline recommendations, this could be considered in certain situations. We argue that guidelines do only as their name suggests-provide guidance. They are not steadfast rules and should not be allowed to dictate our practice.

\section{References}

1. Guo MH, Appoo JJ, Hendry P, Masters R, Chu MWA, Ouzounian M, et al. Knowledge, attitudes, and practice preferences in the surgical threshold for ascending aortic aneurysm among Canadian cardiac surgeons. J Thorac Cardiovasc Surg. 2023; 165:17-25.e2. 
2. Boodhwani M, Andelfinger G, Leipsic J, Lindsay T, McMurtry MS, Therrien J, et al. Canadian Cardiovascular Society position statement on the management of thoracic aortic disease. Can J Cardiol. 2014;30:577-89.

3. Erbel R, Aboyans V, Boileau C, Bossone E, Di Bartolomeo R, Eggebrecht H, et al. 2014 ESC guidelines on the diagnosis and treatment of aortic diseases: document covering acute and chronic aortic diseases of the thoracic and abdominal aorta of the adult. The task force for the diagnosis and treatment of aortic diseases of the European Society of Cardiology (ESC). Eur Heart J. 2014;35:2873-926.

4. Hiratzka LF, Bakris GL, Beckman JA, Bersin RM, Carr VF, Casey DE Jr, et al. 2010 ACCF/AHA/AATS/ACR/ASA/SCA/SCAI/SIR/STS/SVM guidelines for the diagnosis and management of patients with thoracic aortic disease: a report of the American College of Cardiology Foundation/American Heart Association task force on practice guidelines, American Association for Thoracic Surgery, American College of Radiology, American Stroke Association, Society of Cardiovascular Anesthesiologists, Society for Cardiovascular Angiography and Interventions, Society of Interventional Radiology, Society of Thoracic Surgeons, and Society for Vascular Medicine. Circulation. 2010;121:e266-369.

5. Ziganshin BA, Zafar MA, Elefteriades JA. Descending threshold for ascending aortic aneurysmectomy: is it time for a "left-shift" in guidelines? J Thorac Cardiovasc Surg. 2019;157:37-42.
See Article page 17

\section{Commentary: Cardiac surgeons adhere to societal guidelines for aortic surgery... sometimes}

\author{
Christopher Lau, MD, and Mario Gaudino, MD
}

"If all of your friends jumped off a bridge, would you jump too?" is a question that many will remember from their childhood, but the relevance of its meaning applies throughout life. In medicine and surgery, the fact that many people treat patients a certain way does not mean that it is the correct or best way. Although there is an inherent tendency to treat patients based on how our mentors did it, what our colleagues say, and what we are accustomed to, the ultimate goal is to treat patients based on scientific evidence. In this issue of the Journal, Guo and colleagues ${ }^{1}$ present the results of a survey regarding the practice patterns and indications for aortic aneurysm repair among Canadian surgeons. Although we should not deduce any information on how to treat patients from this survey, it does demonstrate the lack of equipoise among cardiac surgeons regarding criteria for aortic interventions. How much of this is due to a lack of knowledge about aortic guidelines rather than a true disagreement over which aortic

From the Department of Cardiothoracic Surgery, Weill Cornell Medicine, New York, NY.

Disclosures: The authors reported no conflicts of interest.

The Journal policy requires editors and reviewers to disclose conflicts of interest and to decline handling or reviewing manuscripts for which they may have a conflict of interest. The editors and reviewers of this article have no conflicts of interest.

Received for publication Jan 28, 2021; revisions received Jan 28, 2021; accepted for publication Jan 28, 2021; available ahead of print Feb 4, 2021.

Address for reprints: Mario Gaudino, MD, Department of Cardiothoracic Surgery, Weill Cornell Medicine, 525 East 68th St, New York, NY 10065 (E-mail: mfg9004@med.cornell.edu).

J Thorac Cardiovasc Surg 2023;165:29-30

$0022-5223 / \$ 36.00$

Copyright (c) 2021 by The American Association for Thoracic Surgery

https://doi.org/10.1016/j.jtcvs.2021.01.123
Check for updates

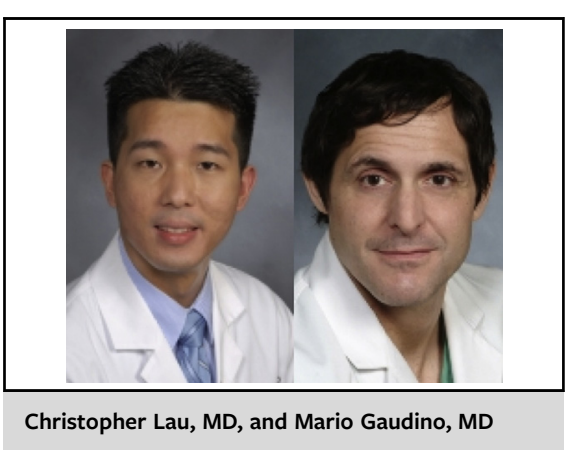

CENTRAL MESSAGE

The practice pattern and criteria

for aortic interventions vary

among cardiac surgeons, and

equipoise regarding when to

intervene is lacking.

measurement or index is the most accurate predictor of adverse aortic events is impossible to know.

A survey such as this has many limitations. In an effort to obtain as many responses as possible from all Canadian cardiac surgeons, the content of the survey is limited to lessen the burden of completing it. The authors included body surface area in the base case information, and they seem to have a predilection for using aortic size index. However, they do not include the necessary information for other aortic parameters that surgeons may use, such as aortic height index, aortic length, or cross-sectional area. $^{2}$ The individual response rate is missing nearly one-half of the surgeons, and some of those who responded performed no aortic aneurysm repairs. Whether the opinions of surgeons who do not actually treat the disease matters is debatable. Identifying information is optional to preserve privacy, so we may not know the volume or experience level of the surgeon. Finally, the authors compare high-volume and 